\title{
Seismic evaluation method for existing reinforced concrete buildings in North of Morocco
}

\author{
Seif-eddine Cherif • Mimoun Chourak • Mohammed Abed • Luis Pujades
}

\begin{abstract}
The purpose of this study is to seismically evaluate reinforced concrete buildings in the northern region of Morocco. In the past, the area have suffered from numerous earthquakes, lately the 2004 earthquake near the city of $\mathrm{Al} \mathrm{Hoceima} \mathrm{(Mw}$ of 6.4 causing more than 600 fatalities) and the region is constantly subject to seismic threats. A total number of 2746 residential buildings from the cities of Al Hoceima and Imzouren have been investigated for the purposes of this study. The proposed method adapts the Japanese Seismic Index Method making it more time-efficient and tuned to the context of the Moroccan construction. The method is based on a visual inspection of buildings and an in-depth insight of how constructions are designed and built in the region. The results show that Imzouren is more exposed to damage than the city of Al Hoceima is, mainly due to the soil nature. The method also shows that as the building's height increases, it becomes more vulnerable. Furthermore, constructions that comply with the seismic regulations have a significant capacity to withstand damage without collapsing unlike other non-engineered buildings that have an almost non-existent ductility and can collapse soon during intense earthquakes.
\end{abstract}

Keywords: Seismic vulnerability $・$ Index method $\bullet$ Capacity curves $\bullet$ Al Hoceima $・$ Imzouren

Acknowledgements This research benefited from the ICTP-OEA (Trieste) Programme in the framework of the North African Group for Earthquake and Tsunami studies (NAGET) activities.

\section{Introduction}

A great number of procedures have been proposed to estimate the seismic vulnerability of existing buildings at multiple scales, where the complexity and accuracy of the method being closely related to the intended scale, regional, city or local, of the studied area. For a city level, the simplest and quickest way is a walk-down survey or street survey (FEMA 154, FEMA 310), which is preferred mostly for time-efficiency. This type of procedures requires a superficial inspection of the buildings in order to evaluate their external aspects such as: age, number of floors, presence/absence of soft stories, short columns, etc. Then, the inspected buildings are catalogued into different classes ranging from buildings exposed to extensive damage (high-vulnerability) to buildings considered safe (low-vulnerability) against seismic activity in a given region.

More complex and in-depth methods require additional information, like data on the size and orientation of the structural elements, material properties and layouts, among other information. It often may entail an internal inspection of the buildings and a review of the formwork and reinforcement drawings. The Seismic Index Method (JBDPA 2001; Hassan

S.Cherif

Département de Géologie, Faculté des Sciences, Université Mohammed Premier

BP 71760000 Oujda Maroc

e-mail : seif.cherif.00@gmail.com

telephone : +212699929208

M.Chourak

Ecole Nationale des Sciences Appliquées Oujda, Université Mohammed Premier

BP 669, Oujda 60000, Maroc

M.Abed

Université de Blida, Algérie

Route de Soumâa, BP 270, Blida 09000, Algérie

L.Pujades

Department of Geotechnical Engineering and Geosciences, Civil Engineering School, Technical

University of Catalonia, Edificio D2, Campus Norte UPC, Jordi Girona 1-3, 08034 Barcelona, Spain 
and Sozen 1997; Yakut 2004; Ozdemir 2005) and nonlinear static or dynamic procedures using software like SAP2000 (Computers and Structures 1997) and DRAIN-2DX (Prakash et al. 1993) are among the most widely used techniques that fall into this category.

In this study, the main objective is to elaborate a technique as easy to consider as a street survey, but more precise and more adapted to the context of the Moroccan reinforced concrete construction. The study region is limited to residential reinforced concrete buildings in the cities of Al Hoceima and Imzouren in north of Morocco. The target area is the most seismically active at the national level (Cherkaoui et al. 1990; El Alami et al. 1998; Bezzeghoud and Buforn 1999) and has suffered severe damage after recent earthquakes, in 1994 and especially in 2004 (Tahayt et al. 2009). According to seismic reports in the aftermath of the February $24^{\text {th }}$, 2004 earthquake (Goula and Gonzalez 2004; Jabour et al. 2004; Cherkaoui and Harnafi 2005), observations have indicated that the main causes of damage in reinforced concrete buildings were related to the following two main causes: i) scarce knowledge or regard for the soil nature prior to building construction and ii) lack of supervision and technical control during building construction. The poor supervision during the building construction is more related to the construction technique than quality of building materials. In fact, one of the main issues is the linking of the structural elements through steel rebar which is not thoroughly controlled. The quality of concrete can also be an issue but only in rare cases, since there is usually a double checking of its quality through testing concrete samples. A first quality control, realized by an internal laboratory belonging to the construction company. A second checking is planned in an unexpected way, by an external laboratory hired by the client to carry out the same mission.

Both cities of Imzouren and Al Hoceima are modern $20^{\text {th }}$ century establishments, where residential buildings are often RC moment frame low- to mid-rise structures. For this reason, the Japanese method (JBDPA 2001) seems to be an interesting tool for the seismic evaluation of RC buildings in the study area. However, since an internal visual inspection of the structural elements was impossible in our case, building models were developed instead, according to the construction customs and requirements. The advantage of the method being a quick screening method that is based on strong knowledge of the design followed in the region for the internal structural elements. This way, the method follows the same structural procedure than the Japanese method. Although the method as proposed herein is not as accurate as the Japanese method, it is much less time-consuming and more precise than quick screenings based methods.

A comparison of the procedure developed in this study with other statistical methods (Cherif et al. 2017), also adapted to the Moroccan construction, shows that the observed damage pattern in the aftermath of the 2004 earthquake is more in concordance with the current study. As a matter of fact, Imzouren is more likely to suffer greater damage than $\mathrm{Al}$ Hoceima, mainly due to local soil effects in the eastern region and also to more improper configuration of structural systems. Furthermore, higher buildings are more likely to receive damage, because of the unreliable seismic performance of RC moment frames for buildings with more than 4 stories. The same understanding was reached in seismic reports in 2004, where many destroyed RC buildings had more than 4 floors.

The results of this study will be shared with the city planners and risk managers in the northern region of Morocco, in order to shed some light on the shortcomings of residential buildings and to provide key issues for improving their dynamic response to future seismic loads.

\section{Methodology}

The study initially started with a preliminary survey in the cities, in order to determine the best method for assessing the residential buildings, and then judging the adaptability of the Seismic index Method (JBDPA 2001). The main approach from the original method that needed to be modified was the internal building inspection, which would normally allow determining the shear resistance of the vertical elements, as well as identifying some of the irregularity and damage parameters. This aspect of the original study (JBDPA 2001) was replaced by an external investigation of the residential buildings coupled with generating 3D building models according to the existent structural typologies, both of which will be further explained subsequently. Finally, specific values, representing the ability of buildings to sustain damage following a seismic crisis, are allocated for each building. 


\subsection{Building inspection}

As stated before, the study started with a preliminary survey, of which the results showed that residential buildings in $\mathrm{Al}$ Hoceima and Imzouren had similar features. For instance, most dwellings are reinforced concrete moment frame structures with regular forms as it can be seen in Figure 3. They are usually low-rise structures built on fairly small floor areas $\left(100 \mathrm{~m}^{2}\right.$ to $\left.150 \mathrm{~m}^{2}\right)$ with 3 to 4 stories without ever exceeding 6 floors (Fig. 4). Following these results, we convened that an external building inspection supported by a good knowledge and simulation of the existent residential buildings constitute an adequate alternative to the internal building inspection. The planned inspection provides information on building geometry and structure, which would allow determining the suitable building model, in addition to complementary data such as existent irregularities and apparent damage.

The investigation targeted residential buildings spread throughout both cities of Al Hoceima and Imzouren (Fig. 1 and Fig. 2). A total number of 2746 buildings were investigated for the purposes of this study: 921 buildings in Al Hoceima (representing $8 \%$ of the total number of residential buildings in the city) and 1825 buildings in Imzouren (representing $35 \%$ of the total number of residential buildings in the city). On the basis of these statistics, the targeted buildings are considered to be representative of the residential construction unit in both cities.

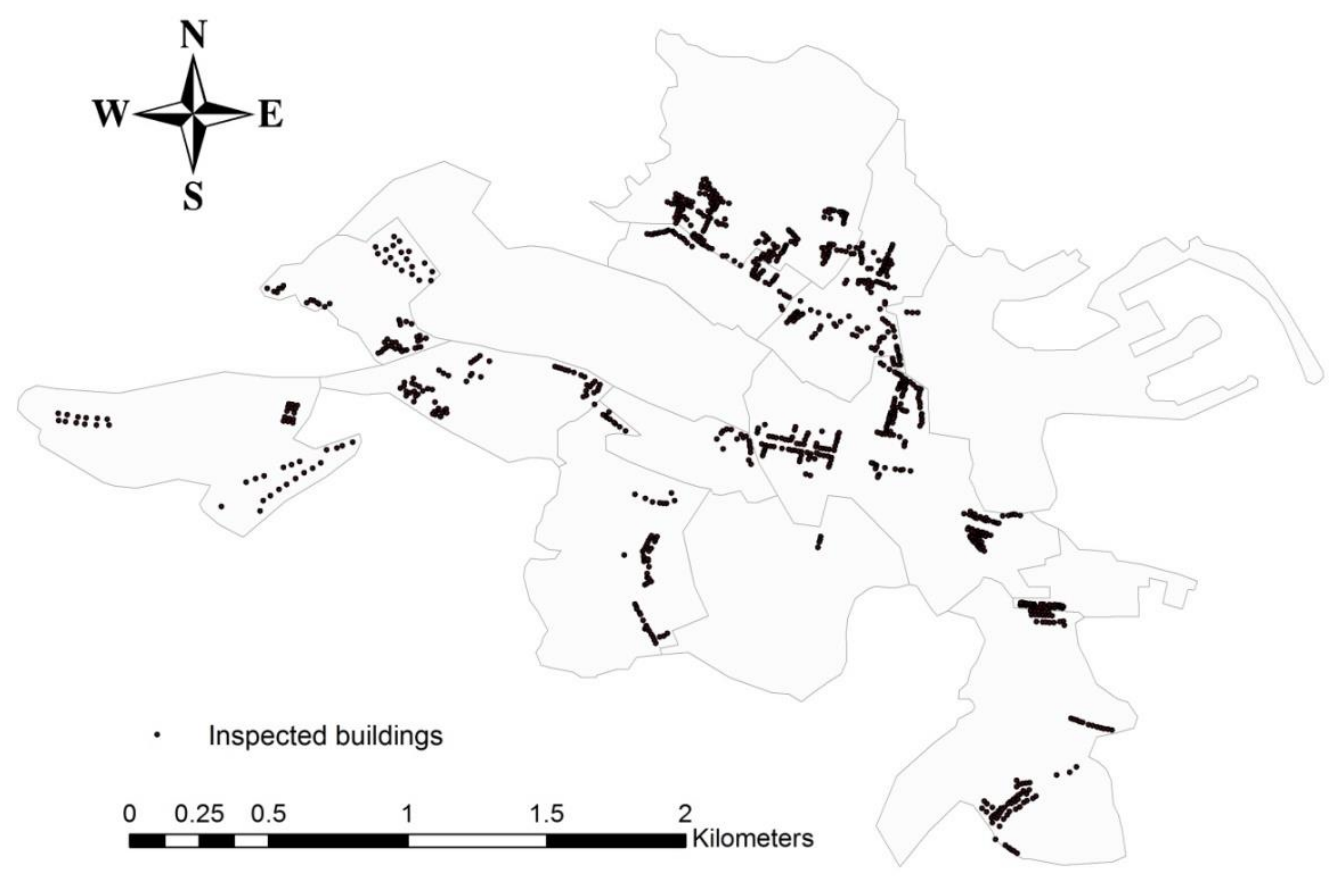

Fig. 1 Inspected buildings in the city of Al Hoceima 


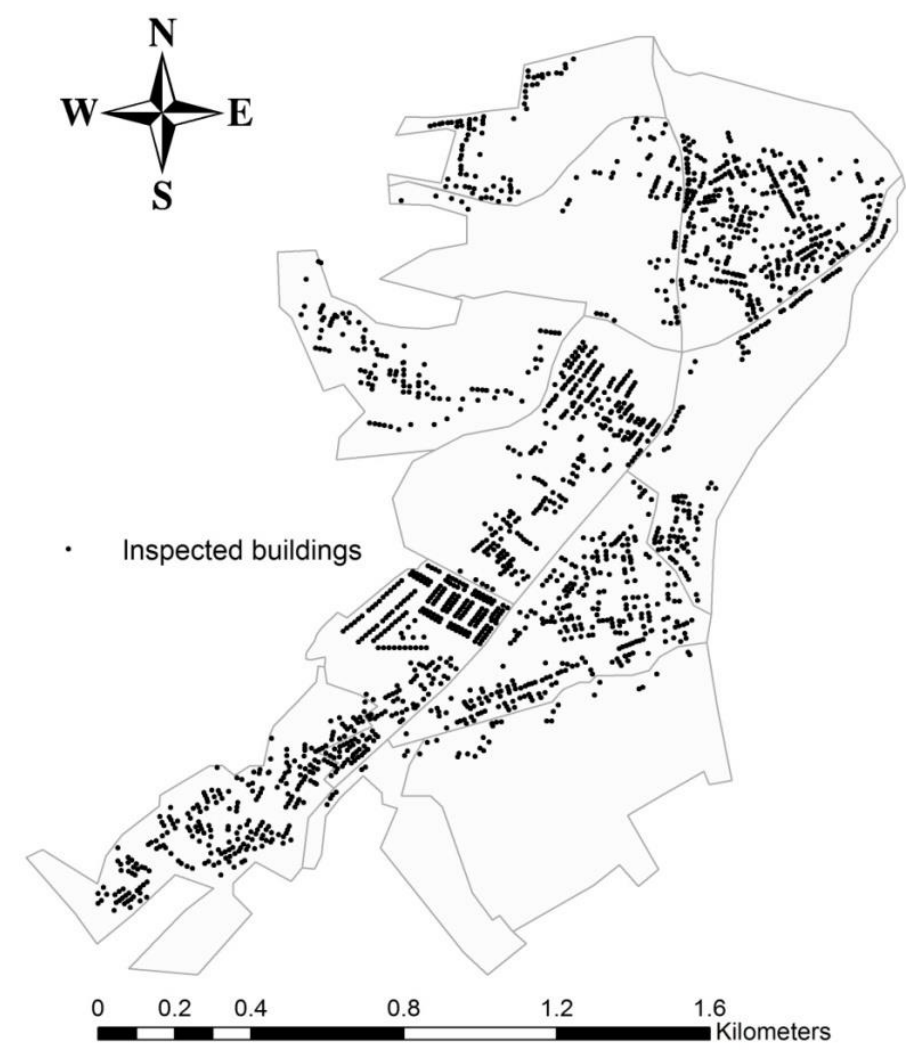

Fig. 2 Inspected buildings in the city of Imzouren

The building inspection focused on three important aspects:

- The structural aspect, which is related to the typology of the building and reflects the basic seismic performance of the structure. Code level, construction period and number of floors are the main parameters to be determined.

- Irregularity aspect, which takes into account the effects of the shape complexity and the unbalanced stiffness distribution, such as the presence of soft-story, short columns, etc.

- Deterioration aspect, which takes into account the effects of the apparent structural defects such as cracking, deflection, aging as well as the like ones.

The team was deployed in the cities with evaluation sheets containing the aspects mentioned above. Each aspect groups a set of parameters to whether determine or verify their existence.
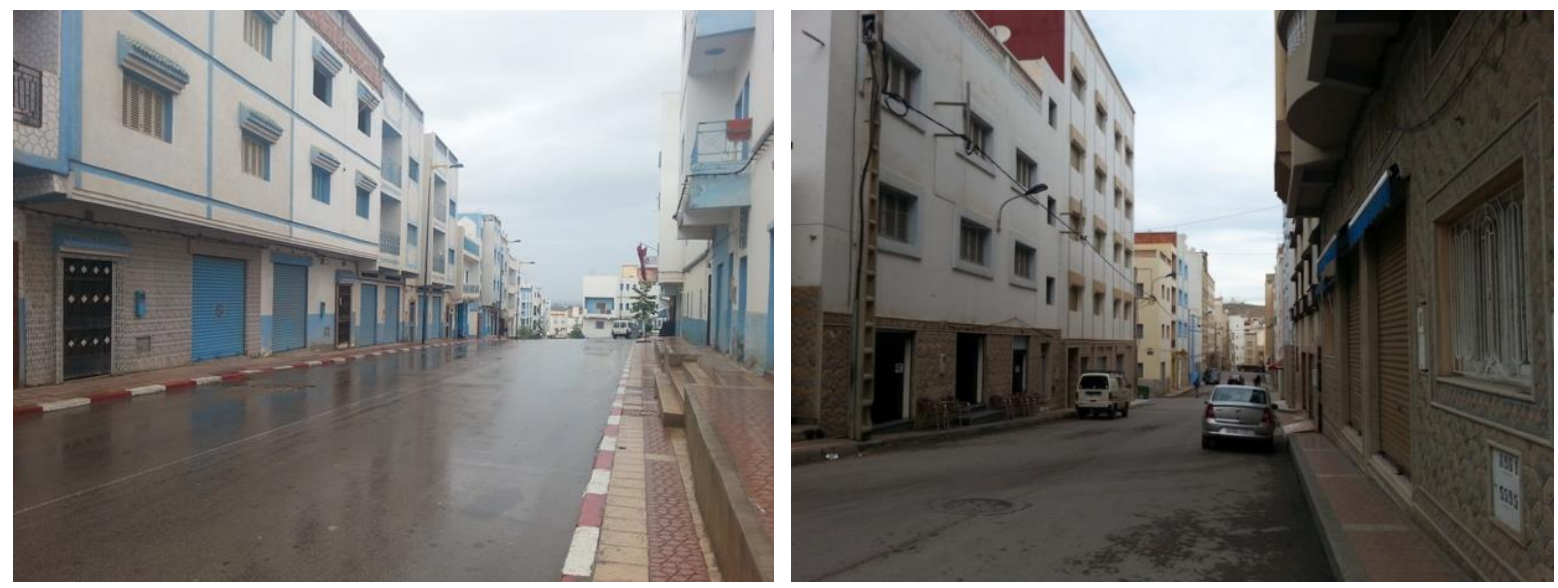

Fig. 3 Examples of residential buildings in Al Hoceima and Imzouren 


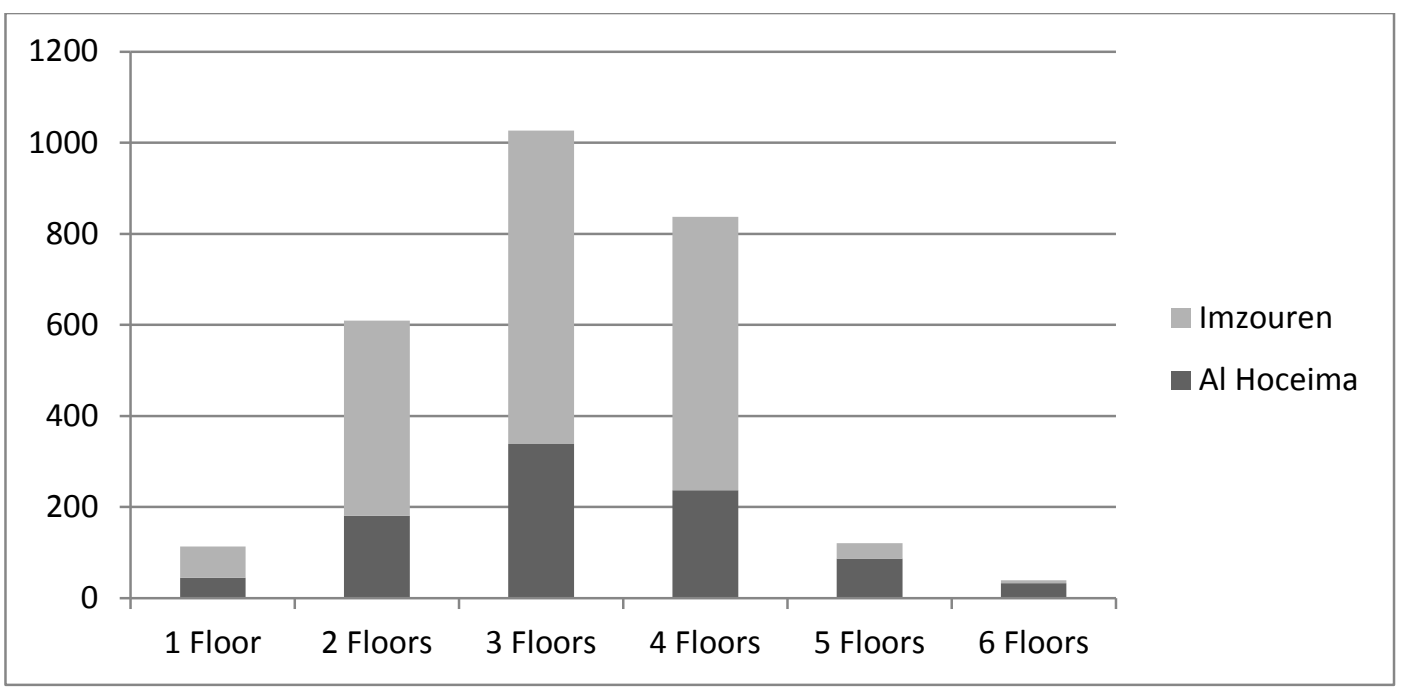

Fig. 4 Distribution of building heights in Al Hoceima and Imzouren

\subsection{Building models}

Building models were chosen as an alternative to an internal investigation of buildings in order to evaluate the characteristics of the structural elements. This choice was considered more appropriate for convenience and timeefficiency on one hand. On the other hand, given the state of the existent residential building stock that showed similarities in geometry and structure.

The building models were developed based on:

- Observations of existent residential buildings and construction sites during on-site investigation.

- Inspection of the structural elements and analysis of the reinforcement plans of some buildings in $\mathrm{Al} \mathrm{Hoceima} \mathrm{and}$ Imzouren.

- Information from consulting civil engineering offices working on residential buildings in the region. Such as loading calculations for residential buildings, structural elements computations, the used software, national applied regulations and used complementary European regulations.

Like in some developing countries, priority is given to the cost of building materials over construction quality. For instance, the cross-sectional area of columns changes at every story if the loading is supported, which could compromise the column strength (internal forces at joints).

36 models were generated based on the following parameters, which are directly determined from the survey sheets gathered from the field investigation:

- Number of stories: 1 to 6 stories.

- Period of construction: before 1991, between 1991 and 2002, after 2002 (Table 1). Constructions were built with different types of materials (steel and concrete) depending on the period of construction. For instance, Fe E 235 steel rebar was commonly used before 1991, while Fe E 500 was more frequently used after the 2000s. Also, concrete compression strength is taken equal to $22 \mathrm{MPa}$ for buildings with seismic code (After RPS2000) and $16 \mathrm{MPa}$ (Before RPS2000) for those without seismic code. This assumption of course is only a proxy to real strength values. However, these two values (16MPa and $22 \mathrm{MPa}$ ) are target values for both construction company and client. Any value below would not respect regulations, and values above would lead to unnecessary additional costs.

- Seismic code: there is only one national seismic code (R.P.S. 2000) which has been applied since 2002 and was revised in 2011 (R.P.S. 2000, Version 2011). Buildings respecting the seismic code are designed to support seismic loads and they are projected essentially in the cross-sectional area of the columns (Fig. 5, Table 2 and Table 3). It is important to note that buildings designed and constructed according to seismo-resistant provisions have not been built necessarily after 2002; older buildings may sometimes be reinforced or were designed according to other seismic regulations like, for instance, PS92 (1995). 
As it is shown in Figure 5, the floor area of the built models has a rectangular shape and is equal to $12 \mathrm{~m} \times 10 \mathrm{~m}$. The development plans of the residential areas in the two cities have an area varying between $100 \mathrm{~m}^{2}$ and $150 \mathrm{~m}^{2}$, so considering all models having a $120 \mathrm{~m}^{2}$ floor area was both suitable and convenient for the representation of these structures. The structural nature of the models is an RC frame, since it is the main type found in residential dwellings. An emphasis was given to the vertical structural elements given their importance in resisting horizontal loads. Tables 2 and 3 show the cross sectional area and disposition of steel rebar for the adopted 3D models. The calculation of these parameters was similar to the one accomplished by design offices. P4 are the strongest columns and P1 are the weakest ones. P2 and P3 are almost similar, the difference being related to the distance between columns.

Table 1 Construction material characteristics for defined periods

\begin{tabular}{lll}
\hline Construction period & Concrete strength & Steel rebar \\
\hline Period I (Pre 1991) & $16 \mathrm{MPa}$ & Fe E 235 \\
Period II (1991-2002) & $16 \mathrm{MPa}$ & Fe E 400 \\
Period III (Post 2002) & $22 \mathrm{MPa}$ & Fe E 500 \\
\hline
\end{tabular}

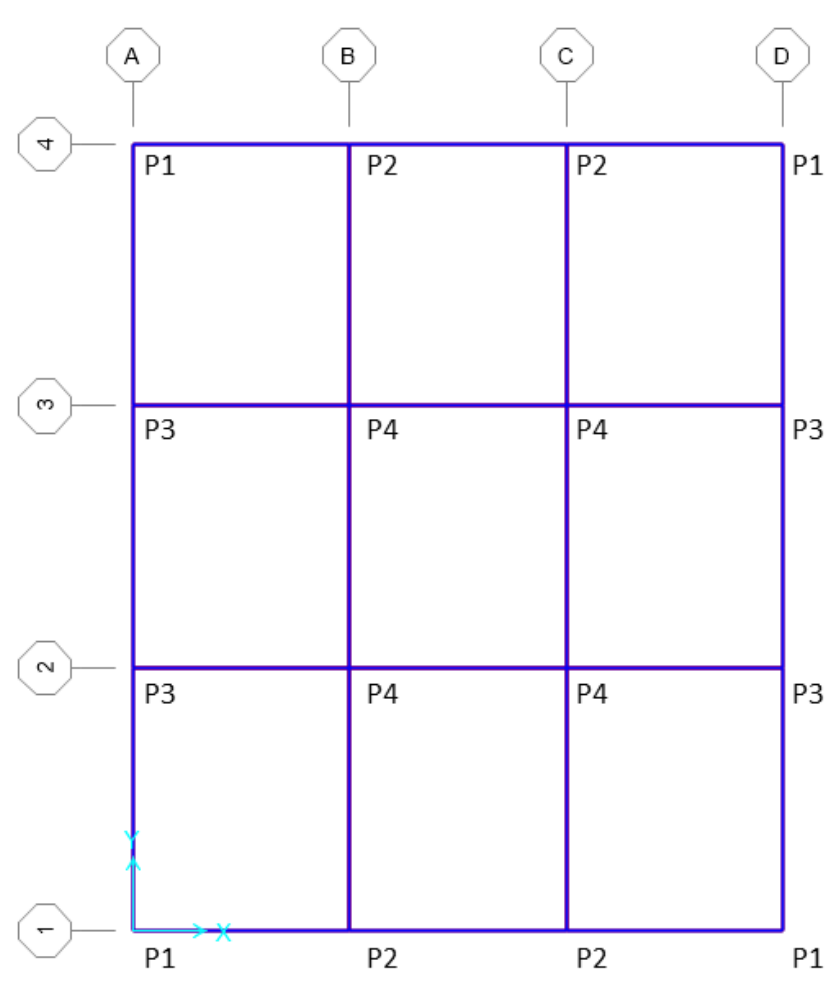

Fig. 5 Distribution of column types for constructed models

Table 2 Cross-sectional area of columns and adopted steel rebar for buildings with seismic code

\begin{tabular}{|c|c|c|c|c|c|c|}
\hline Cross-sectional area $(\mathrm{cm} 2)$ & Floor 1 & Floor 2 & Floor 3 & Floor 4 & Floor 5 & Floor 6 \\
\hline $\mathbf{P 1}$ & $30 \times 30$ & $30 \times 30$ & $25 \times 30$ & $25 \times 25$ & $25 \times 25$ & $25 \times 25$ \\
\hline $\mathbf{P 2}$ & $30 \times 40$ & $25 \times 40$ & $25 \times 40$ & $25 \times 30$ & $25 \times 30$ & $25 \times 25$ \\
\hline P3 & $30 \times 40$ & $25 \times 40$ & $25 \times 40$ & $25 \times 35$ & $25 \times 30$ & $25 \times 25$ \\
\hline P4 & $45 \times 45$ & $40 \times 40$ & $35 \times 35$ & $35 \times 35$ & $30 \times 30$ & $25 \times 25$ \\
\hline Steel rebar & Floor 1 & Floor 2 & Floor 3 & Floor 4 & Floor 5 & Floor 6 \\
\hline $\mathbf{P 1}$ & $6 \mathrm{~T} 14$ & $6 \mathrm{~T} 14$ & $4 \mathrm{~T} 14+2 \mathrm{~T} 12$ & $6 \mathrm{~T} 12$ & $6 \mathrm{~T} 12$ & $6 \mathrm{~T} 12$ \\
\hline $\mathbf{P 2}$ & $8 \mathrm{~T} 14$ & $6 \mathrm{~T} 14$ & $6 \mathrm{~T} 14$ & $4 \mathrm{~T} 14+2 \mathrm{~T} 12$ & $4 \mathrm{~T} 14+2 \mathrm{~T} 12$ & $6 \mathrm{~T} 12$ \\
\hline
\end{tabular}




\begin{tabular}{lllllll} 
P3 & $8 \mathrm{~T} 14$ & $6 \mathrm{~T} 14$ & $6 \mathrm{~T} 14$ & $6 \mathrm{~T} 14$ & $4 \mathrm{~T} 14+2 \mathrm{~T} 12$ & $6 \mathrm{~T} 12$ \\
P4 & $8 \mathrm{~T} 16$ & $8 \mathrm{~T} 16$ & $8 \mathrm{~T} 14$ & $8 \mathrm{~T} 14$ & $6 \mathrm{~T} 14$ & $6 \mathrm{~T} 12$ \\
\hline
\end{tabular}

Table 3 Cross-sectional area of columns and adopted steel rebar for buildings without seismic code

\begin{tabular}{lllllll}
\hline Cross-sectional area $(\mathbf{c m} 2)$ & Floor $\mathbf{1}$ & Floor 2 & Floor 3 & Floor 4 & Floor 5 & Floor 6 \\
\hline P1 & $25 \times 25$ & $25 \times 25$ & $25 \times 25$ & $20 \times 20$ & $20 \times 20$ & $20 \times 20$ \\
P2 & $25 \times 30$ & $25 \times 30$ & $25 \times 25$ & $25 \times 25$ & $20 \times 20$ & $20 \times 20$ \\
P3 & $25 \times 30$ & $25 \times 30$ & $25 \times 25$ & $25 \times 25$ & $20 \times 20$ & $20 \times 20$ \\
P4 & $40 \times 40$ & $35 \times 35$ & $30 \times 30$ & $25 \times 30$ & $25 \times 25$ & $20 \times 20$ \\
\hline & & & & & \\
\hline Steel rebar & Floor $\mathbf{1}$ & Floor 2 & Floor 3 & Floor 4 & Floor 5 & Floor 6 \\
\hline P1 & $4 \mathrm{~T} 12$ & $4 \mathrm{~T} 12$ & $4 \mathrm{~T} 12$ & $4 \mathrm{~T} 10$ & $4 \mathrm{~T} 10$ & $4 \mathrm{~T} 10$ \\
P2 & 6T12 & 6T12 & $4 \mathrm{~T} 12$ & $4 \mathrm{~T} 12$ & $4 \mathrm{~T} 12$ & $4 \mathrm{~T} 12$ \\
P3 & $4 \mathrm{~T} 14+2 \mathrm{~T} 12$ & $6 \mathrm{~T} 12$ & $4 \mathrm{~T} 12$ & $4 \mathrm{~T} 12$ & $4 \mathrm{~T} 10$ & $4 \mathrm{~T} 10$ \\
P4 & $8 \mathrm{~T} 14$ & 6T14 & $6 \mathrm{~T} 14$ & $6 \mathrm{~T} 12$ & $4 \mathrm{~T} 12$ & $4 \mathrm{~T} 10$ \\
\hline
\end{tabular}

\subsection{Seismic building evaluation}

The procedure applied herein is recommended for low-rise and mid-rise reinforced concrete moment frame buildings (JBDPA 2001). The main premise is to approximate the basic seismic performance of the building using the yield and ultimate base-shear capacity from the built models and the code base-shear using the national seismic code R.P.S. 2000. The basic performance is assumed to be exempt from any shape complexity or stiffness unbalance distribution. The negative influence of architectural features on the seismic performance of the buildings is well recognized by the earthquake engineering community (Yakut 2004). Thus, an irregularity index and a time index would be added to the equation in order to calculate the final seismic performance index. This way, the seismic index of the structure $I$ of each building is calculated as follows:

$$
I=B \times R \times T
$$

where $B$ is the basic seismic index of structure, $R$ is the irregularity index and $T$ is the time or deterioration index. All the interest of this equation is to not define the building in a capacity curve but to take also into account the different shape complexities and structural defects the building possesses.

The seismic index I will be assigned two values, $I_{y}$ and $I_{u}$ which are calculated as:

$$
I_{y}=B_{y} \times R \times T \text { and } I_{u}=B_{u} \times R \times T
$$

$B_{y}$ and $B_{u}$ will be further explained in the next section. In general, high values of the seismic index $I$ indicate good seismic behavior of the structure.

\subsubsection{The basic seismic index of structure}

The basic seismic index of structure $B$ represents the basic seismic performance of the building, which, in other words, means its performance excluding irregularities and damage the building may have experienced in the past. $B$ is calculated as follows: 


$$
\begin{aligned}
& B_{y}=\frac{V_{y}}{F} \\
& B_{u}=\frac{V_{u}}{F}
\end{aligned}
$$

where $V_{y}$ is the yield base-shear capacity of the building, $V_{u}$ is the ultimate base-shear capacity of the building

$F$ is the code base shear of the building. It changes for each building model depending on weight and structure. It also depends on building location and site specification. $F$ is determined using the national seismic code RPS (R.P.S. 2000, Version 2011):

$$
F=\frac{v \cdot S \cdot D \cdot I \cdot W}{K}
$$

where $v$ is the assigned velocity coefficient, $S$ is the site coefficient, $D$ is the dynamic amplification factor, $I$ is a priority index, $W$ is the load taken as weight of the structure and $K$ is a ductility factor

$F$ was introduced in the RPS2000 as one of the regulations that needs to be respected in the construction of buildings since 2002. In this study, $F$ is used for all existing buildings, because it acts as a key variant separating a good seismic performance from a weak one, regardless of age of the building or its compliance with the seismic code. In addition, since the value of $F$ depends on structural factors, among others, it may change depending on the studied building model; number of stories and observance of seismic code being the main influencers.

In order to calculate $\mathrm{V}_{\mathrm{y}}$ and $V_{u}$, each building model was subjected to a static nonlinear pushover analysis in the weakest direction (x-direction based on Figure 5) in order to obtain the base shear versus roof displacement curves (Fig. 6).Then, the capacity curves were approximated with a bilinear curve using guidelines given in FEMA 273 (FEMA 1997) like shown in Figure 7. $V_{\mathrm{y}}$ and $V_{u}$ are determined using Table 4, which represents the yield and ultimate base-shear capacity of each of the 36 built models.
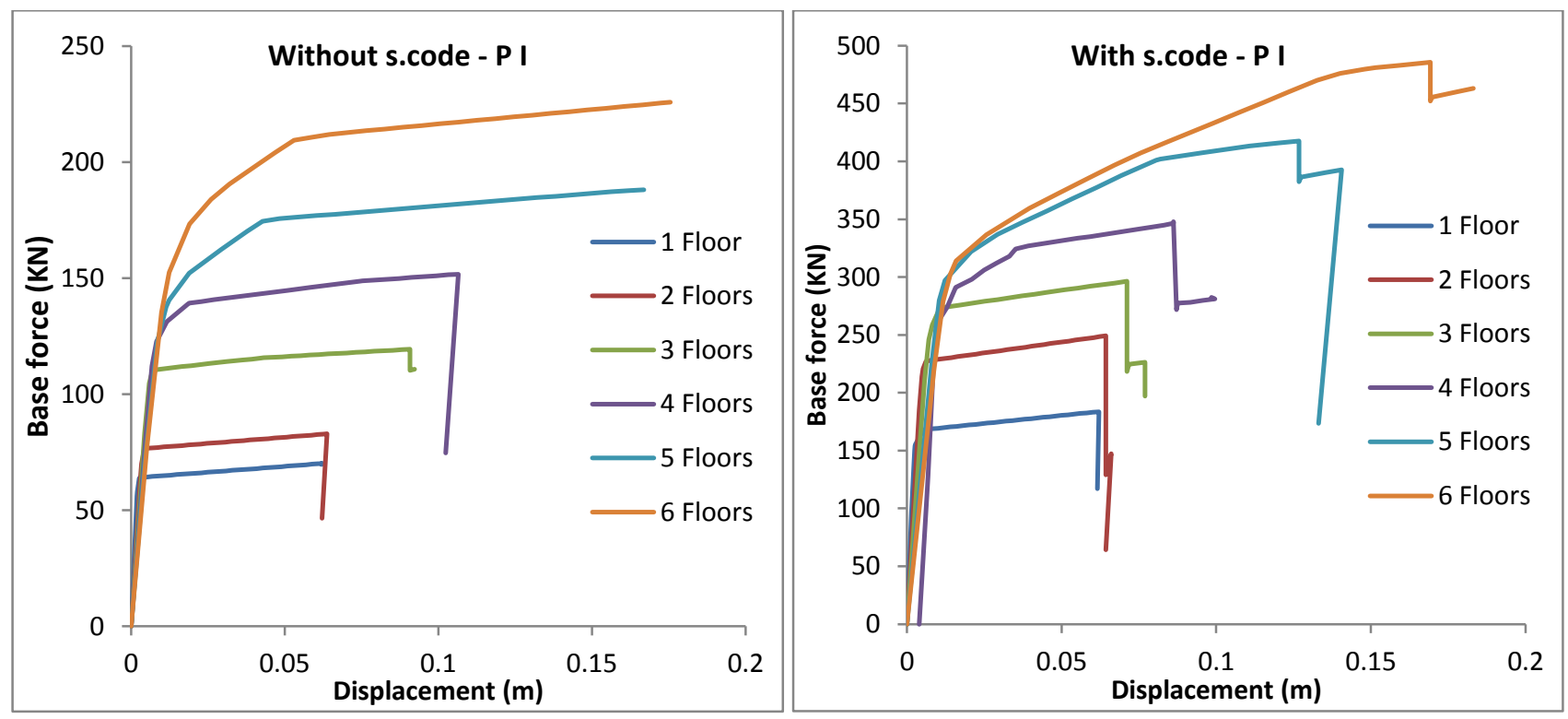

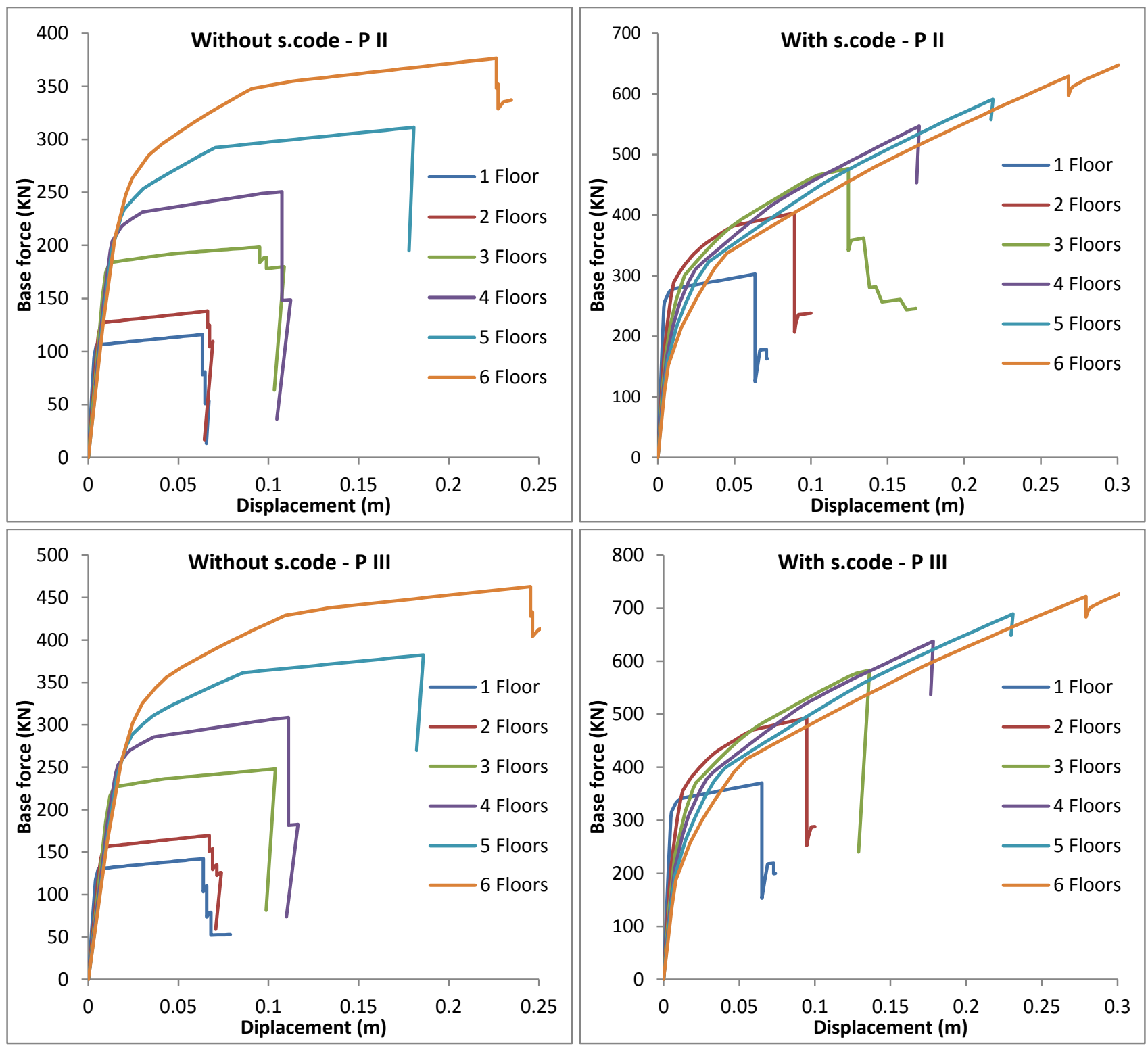

Fig. 6 Pushover capacity curves for the 36 built models

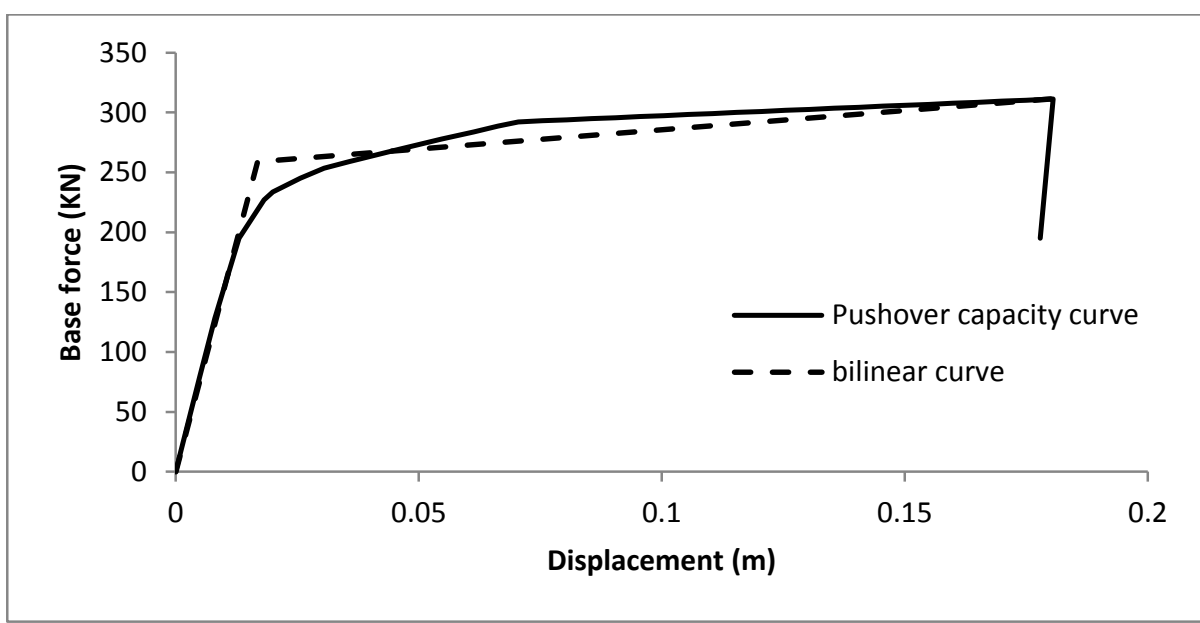

Fig. 7 Example of a bilinear approximation of a pushover capacity curve for 5-storey buildings with seismic code Period II (1991 - 2002) 
Table 4 Yield and ultimate states for the 3D built models

\begin{tabular}{|c|c|c|c|c|c|c|c|c|c|c|c|c|}
\hline \multicolumn{13}{|c|}{ With seismic code } \\
\hline \multirow{2}{*}{$\begin{array}{l}\text { Number } \\
\text { of floors }\end{array}$} & \multicolumn{4}{|c|}{ Period I (Pre 1991) } & \multicolumn{4}{|c|}{ Period II (1991 - 2002) } & \multicolumn{4}{|c|}{ Period III (Post 2002) } \\
\hline & $\begin{array}{l}\text { Dy } \\
(\mathrm{cm})\end{array}$ & $\begin{array}{c}\mathrm{Vy} \\
(\mathrm{KN})\end{array}$ & $\begin{array}{c}\mathrm{Du} \\
(\mathrm{cm})\end{array}$ & $\begin{array}{c}\mathrm{Vu} \\
(\mathrm{KN})\end{array}$ & $\begin{array}{c}\text { Dy } \\
(\mathrm{cm})\end{array}$ & $\begin{array}{c}\mathrm{Vy} \\
(\mathrm{KN})\end{array}$ & $\begin{array}{c}\mathrm{Du} \\
(\mathrm{cm})\end{array}$ & $\begin{array}{c}\mathrm{Vu} \\
(\mathrm{KN})\end{array}$ & $\begin{array}{l}\text { Dy } \\
(\mathrm{cm})\end{array}$ & $\begin{array}{c}\mathrm{Vy} \\
(\mathrm{KN})\end{array}$ & $\begin{array}{c}\mathrm{Du} \\
(\mathrm{cm})\end{array}$ & $\begin{array}{c}\mathrm{Vu} \\
(\mathrm{KN})\end{array}$ \\
\hline 1 Floor & 0.25 & 166.5 & 6.20 & 183.7 & 0.41 & 274.0 & 6.36 & 302.6 & 0.49 & 334.3 & 6.49 & 370.5 \\
\hline 2 Floors & 0.49 & 226.5 & 6.43 & 249.2 & 0.86 & 330.7 & 8.92 & 403.4 & 1.02 & 376.0 & 9.47 & 493.0 \\
\hline 3 Floors & 0.73 & 271.0 & 7.12 & 296.3 & 1.13 & 328.9 & 12.43 & 476.8 & 1.23 & 385.3 & 13.61 & 583.0 \\
\hline 4 Floors & 0.96 & 305.6 & 8.61 & 347.7 & 1.28 & 314.8 & 17.06 & 546.9 & 1.47 & 378.4 & 17.83 & 637.9 \\
\hline 5 Floors & 1.19 & 337.7 & 12.68 & 417.5 & 1.58 & 316.4 & 21.88 & 591.2 & 1.79 & 378.3 & 21.40 & 667.8 \\
\hline 6 Floors & 1.39 & 350.5 & 16.93 & 485.8 & 1.96 & 314.7 & 26.80 & 629.3 & 2.20 & 376.4 & 27.91 & 722.2 \\
\hline \multicolumn{13}{|c|}{ Without seismic code } \\
\hline \multirow{2}{*}{$\begin{array}{l}\text { Number } \\
\text { of floors }\end{array}$} & \multicolumn{4}{|c|}{ Period I (Pre 1991) } & \multicolumn{4}{|c|}{ Period II (1991 - 2002) } & \multicolumn{4}{|c|}{ Period III (Post 2002) } \\
\hline & $\begin{array}{l}\text { Dy } \\
(\mathrm{cm})\end{array}$ & $\begin{array}{c}\mathrm{Vy} \\
(\mathrm{KN})\end{array}$ & $\begin{array}{c}\mathrm{Du} \\
(\mathrm{cm})\end{array}$ & $\begin{array}{c}\mathrm{Vu} \\
(\mathrm{KN})\end{array}$ & $\begin{array}{l}\text { Dy } \\
(\mathrm{cm})\end{array}$ & $\begin{array}{c}\mathrm{Vy} \\
(\mathrm{KN})\end{array}$ & $\begin{array}{c}\mathrm{Du} \\
(\mathrm{cm})\end{array}$ & $\begin{array}{c}\mathrm{Vu} \\
(\mathrm{KN})\end{array}$ & $\begin{array}{c}\text { Dy } \\
(\mathrm{cm})\end{array}$ & $\begin{array}{c}\mathrm{Vy} \\
(\mathrm{KN})\end{array}$ & $\begin{array}{c}\mathrm{Du} \\
(\mathrm{cm})\end{array}$ & $\begin{array}{c}\mathrm{Vu} \\
(\mathrm{KN})\end{array}$ \\
\hline 1 Floor & 0.22 & 64.0 & 6.21 & 70.2 & 0.36 & 105.8 & 6.34 & 116.0 & 0.45 & 129.9 & 6.38 & 142.4 \\
\hline 2 Floors & 0.36 & 76.4 & 6.37 & 82.9 & 0.59 & 126.5 & 6.62 & 138.1 & 0.73 & 155.5 & 6.71 & 169.7 \\
\hline 3 Floors & 0.58 & 111.5 & 9.08 & 119.4 & 0.97 & 185.1 & 9.50 & 198.5 & 1.20 & 228.5 & 10.38 & 248.0 \\
\hline 4 Floors & 0.80 & 137.4 & 10.65 & 151.8 & 1.31 & 224.0 & 10.74 & 250.6 & 1.60 & 274.5 & 11.10 & 308.5 \\
\hline 5 Floors & 1.12 & 165.7 & 16.69 & 188.1 & 1.68 & 259.0 & 18.05 & 311.4 & 2.10 & 325.3 & 18.59 & 382.3 \\
\hline 6 Floors & 1.17 & 193.1 & 17.55 & 225.9 & 2.20 & 313.1 & 22.64 & 376.5 & 2.67 & 381.1 & 24.53 & 463.1 \\
\hline
\end{tabular}

There are similarities between the studied method and the mechanical RISK_UE method (Lagomarsino and Giovinazzi, 2006). They both employ capacity curves to identify damage states. Where RISK_UE method employs the yielding and ultimate displacement to determine damage limit states, to be formerly correlated with the response spectra to identify the performance point, the present study employs instead yielding and ultimate shear capacities, with the seismic demand capacity from the national code, to define the damage states. It is simply due to the fact that seismic demand in the national seismic code (R.P.S. 2000) is presented only in terms of base-shear capacity $F_{\text {code }}$.

\subsubsection{The irregularity index}

The irregularity index $R$ represents the shape complexity effects and the stiffness unbalance distribution that affect the performance of the building. It has been adapted from the Japanese standard (JBDPA 2001) according to the specifications described in the R.P.S. 2000. There are seven items to be determined in order to estimate the irregularity index:

- Regularity: a building is considered regular if the dimensions of protruding or recessed parts do not exceed 0.25 times the dimension of the corresponding side (Fig. 8):

$$
a+b \leq 0.25 \times B
$$

where $a$ is the protruding part, $b$ is the recessed part and $B$ is the length of the corresponding side.

This aspect also addresses the plan symmetry of the building and its exposure to geometrical torsion effect.

- $\quad$ Aspect ratio: the aspect ratio must not exceed the value of 3.5 (Fig. 8): 


$$
\frac{L}{B} \leq 3.5
$$

where $B$ is the length of the short side and $L$ is the length of the large side.

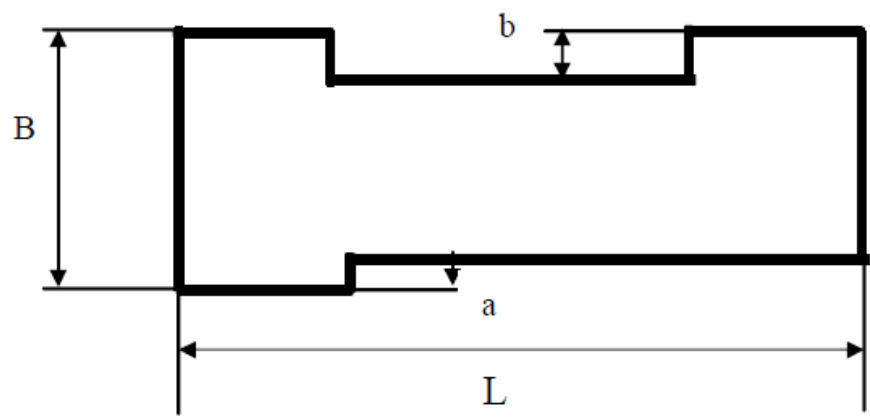

Fig. 8 Top view showing regularity terms

- Expansion joint: the joint width between two blocks should exceed (Fig. 9):

$$
d=\operatorname{Max}(0.003 \mathrm{H}, 5 \mathrm{~cm})
$$

where $H$ is the lowest block height.

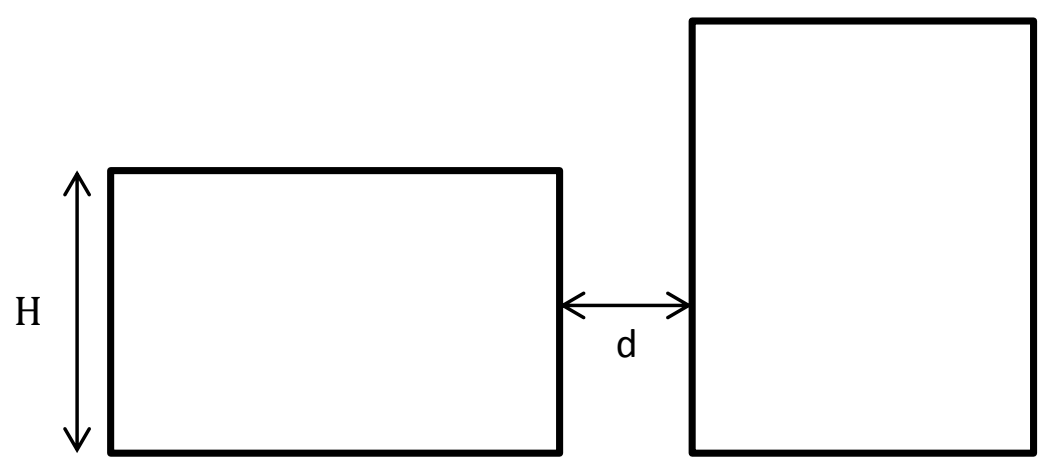

Fig. 9 Terms for expansion joint

- Underground floor: the presence of basements enhances the seismic performance of buildings:

$$
h=\frac{\text { area of the basement }}{\text { area of the building }}
$$

- Story height uniformity: In case of a gradual narrowing of floors, the projection must not exceed $15 \%$ of the level below; without exceeding $25 \%$ for a total withdrawal. In case of a gradual widening, the difference between successive floors should be under $10 \%$, and the global widening shouldn't exceed $20 \%$ :

$$
u=\frac{\text { the height of the concerned story }}{\text { the height of the story below }}
$$

- Soft-story: Ideally, the structure must be the stiffest element and non-structural elements must not compromise the ability of the structure to perform. If the frame has insufficient stiffness, the non-structural partitions act as shear walls since they become loaded by the deformations of the frame. If the ground floor is fragile, undivided and/or has higher columns, a classic soft-storey results, with a stiffer than expected mass over a very weak ground floor. In case of Moroccan structures, classic candidates for soft-storey damage are buildings with open plan shops on the ground floor with densely compartmented housing above. 
- Captive column or short-column: Although the terms have been used interchangeably, the reasons that cause them are completely different. In the former case, the column is affected by the presence of adjoining nonstructural elements. In the latter, the column is made shorter than neighboring columns by horizontal structural elements that frame at mid-height of the column (Guevara and Garcia 2005). Based on earthquake reports on past earthquakes in the country (Corella 2004), captive column effects are much more frequent, caused by adjoining masonry infill walls at the ground floor level. In order to identify a captive-column, the height of the opening $h_{0}$ must not exceed double the width of the adjoining column $w$ as shown in Figure 10. However, column width is sometimes hard to identify when it's hidden behind masonry walls; in this case, captive-columns presence is determined by expert opinion.

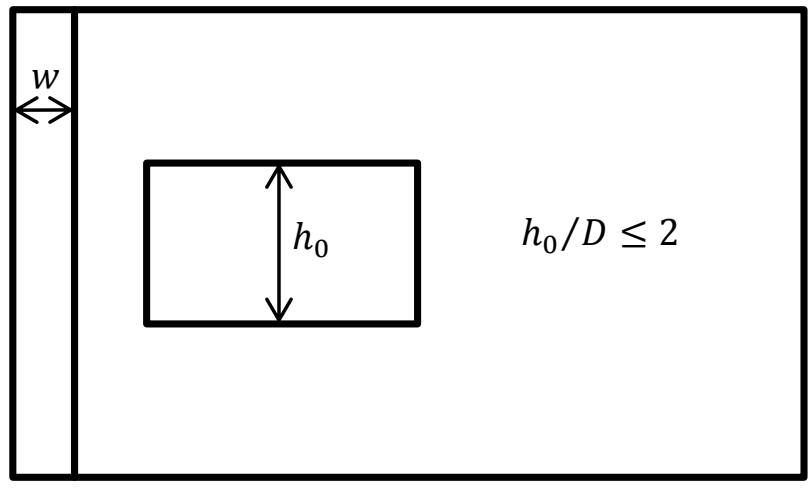

Fig. 10 Case of an extremely short column

Soft-storeys and short-columns are the most common irregularities seen in the area. Sometimes, buildings have a first floor designed for commerce. Therefore, in order to make the business attractive, the first floor has more openings and less masonry infills, which affects its rigidity compared to the other floors. According to seismic reports of the 2004 earthquake (Corella 2004) more than half of the damaged buildings located in the cities of Al Hoceima and Imzouren had short-columns and/or soft-storeys.

The irregularity index $R$ is calculated as the geometric product of items with factors $R_{i}$ calculated as in equation (10), according to the classification given in Table 5:

$$
R=\prod_{i=1}^{7} R_{i}
$$

Table 5 Irregularity parameters $R_{i}$ for calculation of irregularity index $R$

\begin{tabular}{llcc}
\hline $\boldsymbol{R}_{\boldsymbol{i}}$ & Parameter & Description & Value \\
\hline$R_{1}$ & Regularity & Regular building & 1.0 \\
& & Irregular building & 0.9 \\
\hline$R_{2}$ & Plan aspect ratio & $L / B \leq 3.5$ & 1.0 \\
& & $L / B>3.5$ & 0.95 \\
\hline & Expansion joint & If $d<\max (5 \mathrm{~cm} ; 0.003 H):$ & 1.0 \\
$R_{3}$ & & Middle building & 0.95 \\
& & Corner building & 0.9 \\
\hline$R_{4}$ & Underground floor & Header building & 1.1 \\
& & $1.0 \leq h$ & 1.075 \\
\hline$R_{5}$ & Story height uniformity & $0.5 \leq h<1.0$ & 1.05 \\
\hline
\end{tabular}




\begin{tabular}{llcc}
\hline & & $u<0.85$ or $u>1.1$ & 0.95 \\
\hline$R_{6}$ & Soft story & $\begin{array}{c}\text { Open plan shops on the ground floor with densely } \\
\text { compartmented housing above }\end{array}$ & 0.8 \\
\hline$R_{7}$ & Short-columns & $h_{0} / D \leq 2$ & 0.9 \\
\hline
\end{tabular}

\subsubsection{Time index}

The time index, or deterioration index, $T$ represents the effects of the structural defects, such as cracking and deflection, on the seismic performance of the structure. The time index $T$ should be determined based on the inspection results listed in Table 6. The minimum $T_{i}$ value in the table should be taken as the time index T.

Table 6 Time index parameters $T_{i}$

\begin{tabular}{lll}
\hline Item to be checked & Degree & $\mathbf{T}_{\mathbf{i}}$ \\
\hline Deflection & Tilting of a building or obvious uneven settlement & 0.7 \\
& Deflection of beam & 0.9 \\
\hline Soil morphology & Slope & 0.95 \\
& Cliff & 0.9 \\
\hline Cracking in walls and columns & Rain leak with rust of reinforcing bar & 0.8 \\
& Obvious inclined cracking in columns & 0.8 \\
& Countless cracking's in external wall & 0.9 \\
& Rain leak without rust of reinforcing bar & 0.9 \\
\hline Trace of Fire experience & & 0.7 \\
\hline Finishing condition (Bad maintenance) & & 0.9 \\
\hline Not any of the forgoing shortcomings are observed & 1.0 \\
\hline
\end{tabular}

\section{Application of the method}

The seismic evaluation of existing reinforced concrete buildings has been applied to all the inspected buildings in the cities of Al Hoceima and Imzouren. Structures having an index value $I_{y} \geq 1$ mean that they are safe and that, in case of an earthquake, they are likely to suffer no damage. In case of $I_{y}<1$ and $I_{u} \geq 1$, buildings seismic performance is on an uncertain plastic state and they are likely to suffer structural damage but no partial or total collapse. If $I_{u}<1$, it means that the structure, when subjected to a seismic load, fails and it is likely to collapse at any moment.

The first main results show that the average values for $I_{y}$ and $I_{u}$ are equal to 0.71 and 1.02 respectively for the studied buildings, which obviously explains the great numbers of buildings, which were not built according to the present construction and seismic standards, even though the seismic demand is conservative and is higher than what recent observed seismic activity has shown, including the 2004 earthquake.

As for the influence of $B, R$ and $T$ indices on the seismic index value $I$, it should come with no surprise that $I$ and $B$ are strongly correlated (Fig. 11), although the effect of the irregularity index $R$ and the time index $T$ is not insignificant. Their influence can go up to $35 \%$ of the seismic index value for the irregularity index $R$ and up to $25 \%$ for the time index $T$. Figure 12 shows that buildings designed with a seismic code perform better than their counterparts built without codebased considerations, in the elastic and plastic modes. Figure 12 also shows that $I_{y}$ and $I_{u}$ values tend to decrease, with the height of the buildings. This could explain the fact that common practice in the country suggests to add shear walls if the building has more than 4 stories.

In the case of buildings without seismic code, the results show that there is not much variation in $I_{y}$ and $I_{u}$ in cases of buildings without seismic code for I, II and III periods. That's because the base-shear capacity of the building (loading calculations and structural elements design) follows the same pattern as the seismic demand, which leads to a constant 
ratio $\frac{\mathrm{V}}{\mathrm{F}}$. It is related to the fact that building design without seismic code is conducted in a way to resist loading, live and dead load only, and provides the strict minimal sections (for horizontal and vertical elements) for each floor without consideration to enlarge sections for a better linking as an example. This leads to the same discussed ratio whatever the number of floors the building has. We also notice that the dwellings built in II and III periods have close $I_{y}$ and $I_{u}$ results no matter the number of floors. That's because even if there was an upgrade in the quality of construction materials, it was slight enough to not make a difference.
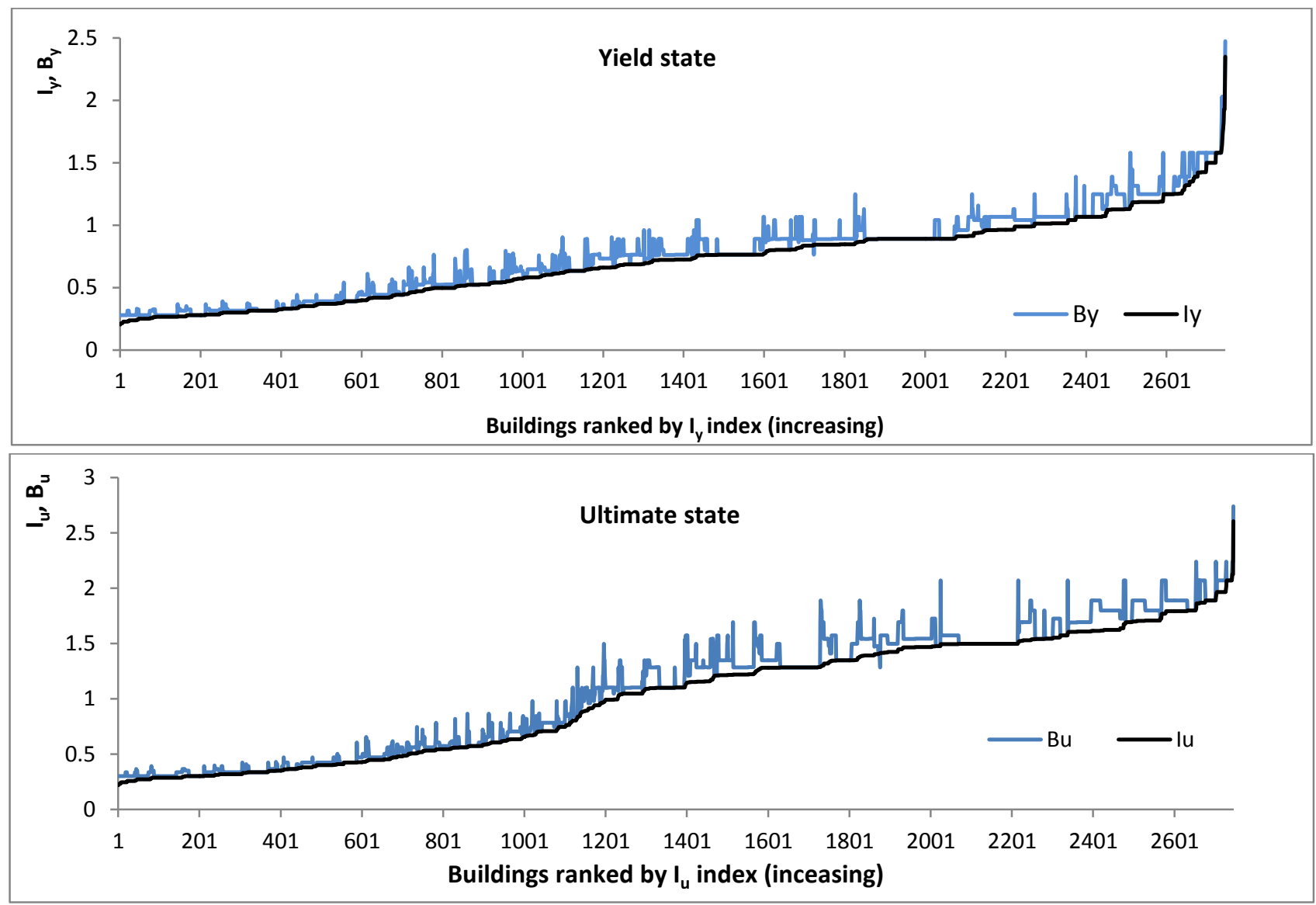

Fig. 11 Variation of the basic seismic indices $B_{y}$ and $B_{u}$

According to the same results, 1 story constructions built in the 2000s and designed with seismic code, perform the best, with an average value of $\mathrm{I}_{\mathrm{y}}=1.9$ and $\mathrm{I}_{\mathrm{u}}=2.11$, while 2 story buildings built before the 1990s without a seismic code perform the worst, with average values of $\mathrm{I}_{\mathrm{y}}=0.30$ and $\mathrm{I}_{\mathrm{u}}=0.33$. It is important to note that $\mathrm{I}_{\mathrm{u}}$ values for 6 story buildings, with seismic code design, built after 2002 (period of construction III) are greater than the values obtained for 3,4 and 5 stories buildings. The main reason is that 6 -storey buildings are located in the most important avenues in the two cities; their owners invest more money in their design and in their construction. That is why, in most cases, they are high quality constructions. 

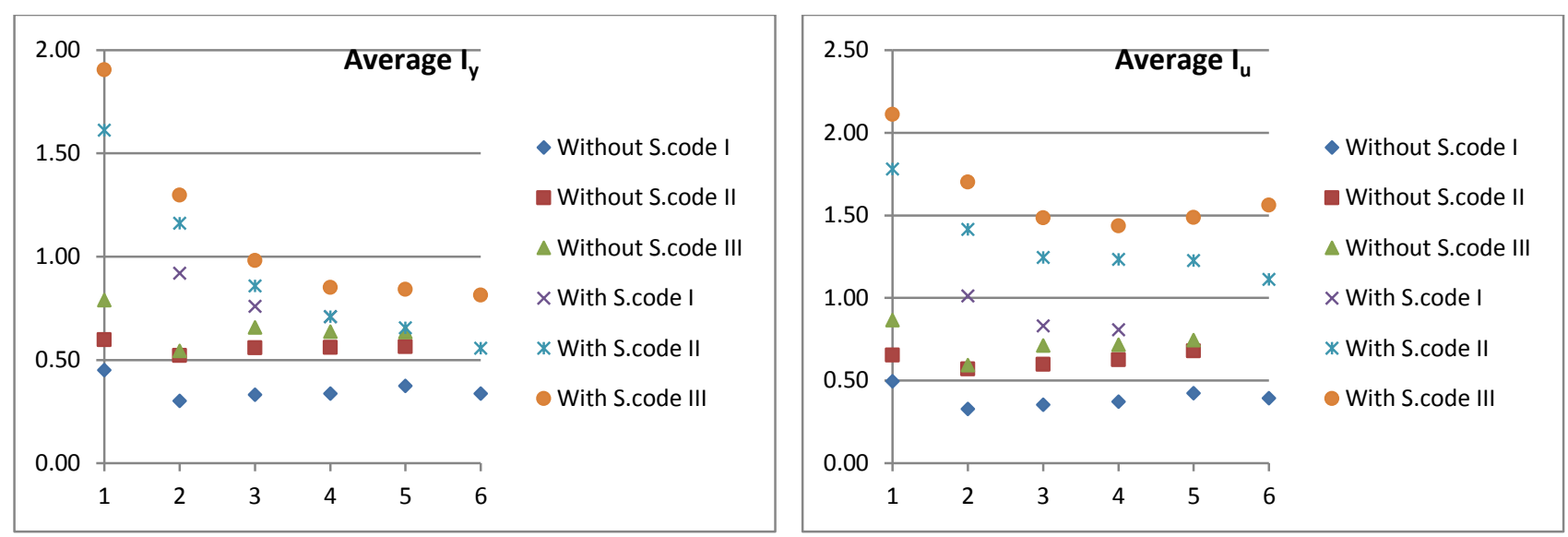

Fig. 12 Average values of $I_{y}$ and $I_{u}$ for the different combinations of floors, construction period and seismic code

According to the national seismic code (R.P.S. 2000), in order to ensure an acceptable level of safety for human life during an earthquake and its aftermath, it is required that the whole structure have a relatively low probability of collapse during the useful life of the building. In other words, it is very important that the structure remains standing during a seismic event, even if it suffers damage. It is exactly what was observed in the results through Figure 13. If one goes to compare $I_{y}$ and $I_{u}$ indices of the buildings designed with seismic code, it is noteworthy that $I_{u}$ values are significantly higher than $I_{y}$ values, which provides an important margin for the building to sustain damage. In contrast, nonengineered buildings show that $I_{y}$ and $I_{u}$ are very close to each other, meaning the building may experience instant collapse, which could be very dangerous for residents who wouldn't have enough time to evacuate.
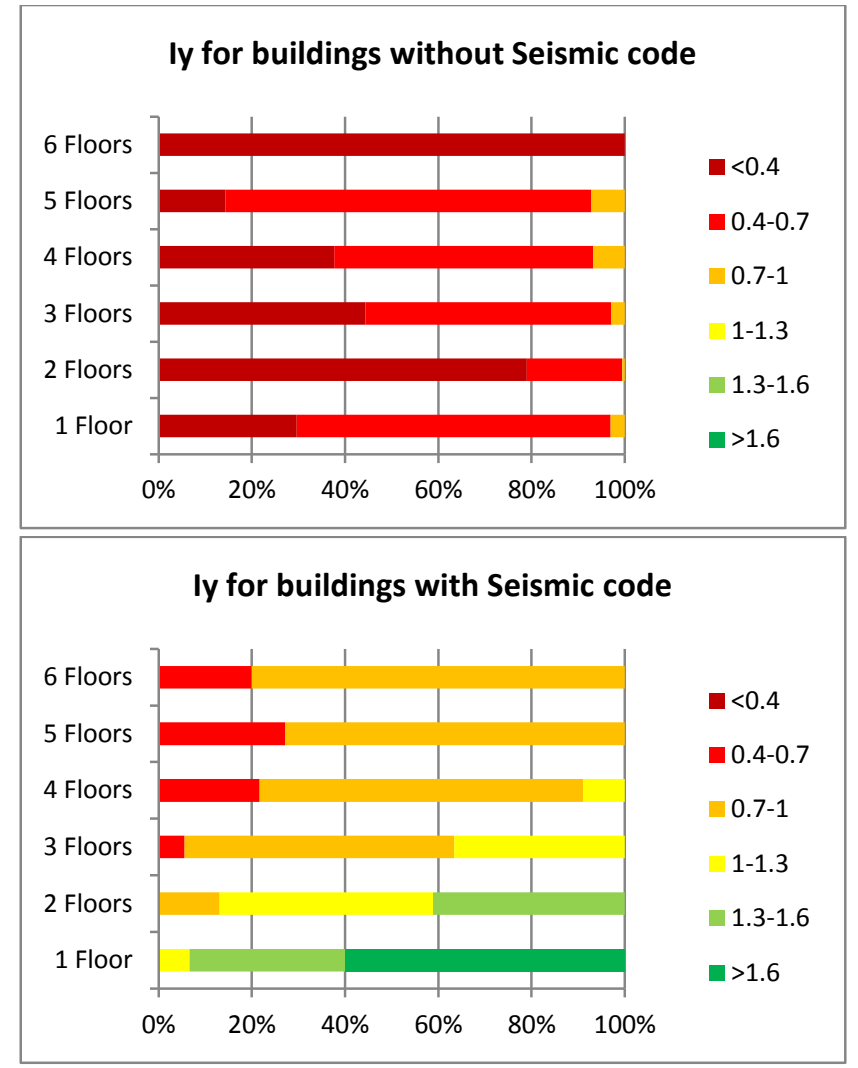

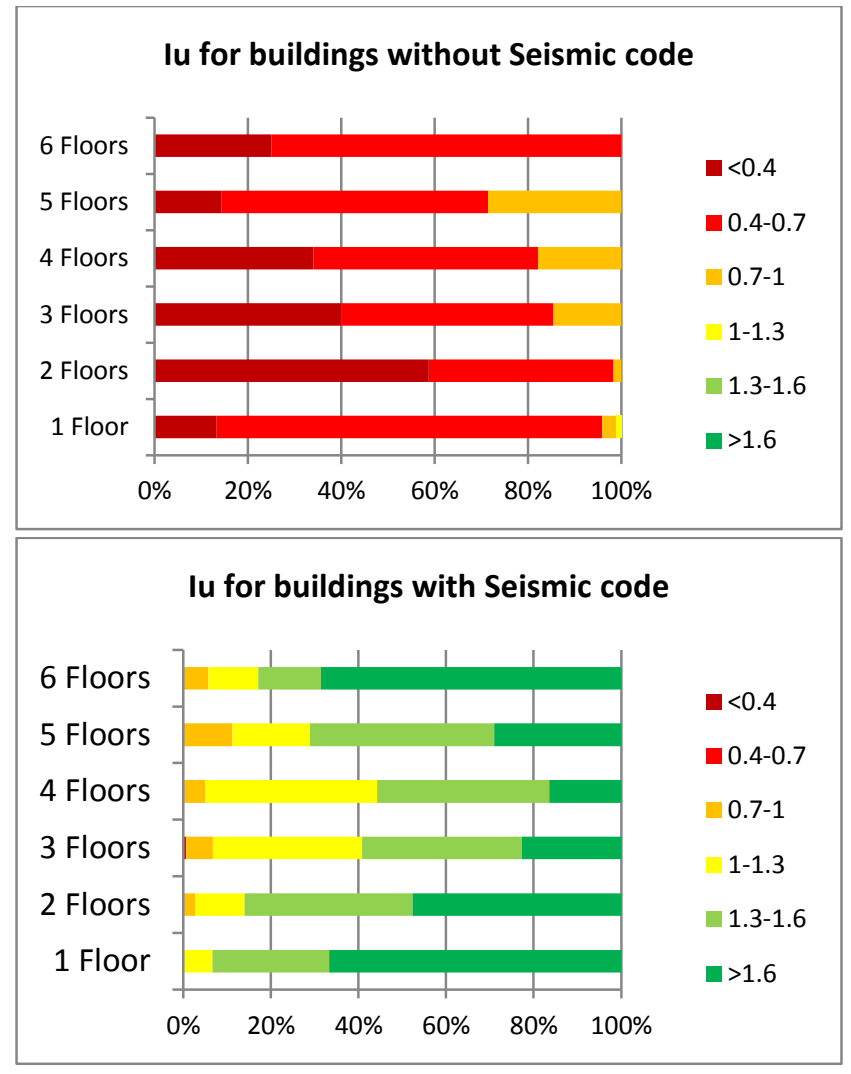

Fig. 13 Building distribution in terms of number of floors and seismic code

If we compare the results between the two cities, Figure 14 shows that the city of Imzouren is potentially more exposed to damage than the city of $\mathrm{Al}$ Hoceima is. The reason is not related to the capacity curves of the residential buildings as one should expect. In fact, if one compares $V_{y}$ and $V_{u}$ values for the two cities, they are relatively close, or even $V_{u}$ values 
of Imzouren buildings are relatively higher. However, the main reason comes from the seismic demand $F_{\text {code }}(5)$. If most parameters do not make a big difference, it is the site coefficient $S$, which reflects the nature of the soil, that creates the disparity of the results between the two cities. The existing buildings in Al hoceima are built on a rocky soil, equivalent to an S1 soil according to the seismic standard (R.P.S. 2000), while the city of Imzouren is built on a softer soil varying from S1 to S3 according to the same standard (Douiri et al. 2014).

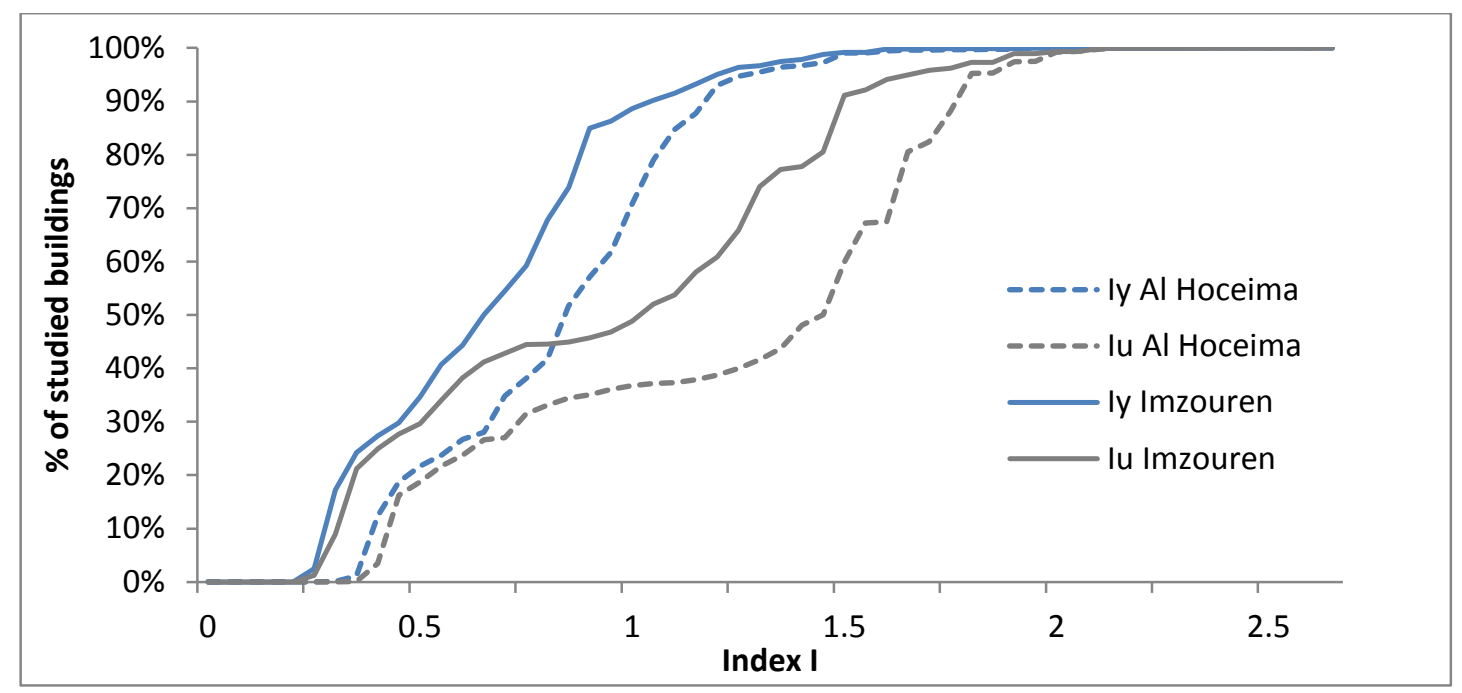

Fig. 14 Distribution of $I_{y}$ and $I_{u}$ values for the cities of Al Hoceima and Imzouren

Regarding $I_{y}$ and $I_{u}$ in Imzouren, Figure 15 shows that the eastern part of the city is more vulnerable, due to the nature of the site and soil effects in these areas (Douiri et al. 2014; Cherif et al. 2017). Values of $I_{y}$ index range between 0.2 and 2.35 with an average value of 0.66 while $I_{u}$ index has values ranging between 0.22 and 2.6 , with an average value of 0.93. As for the city of $\mathrm{Al}$ Hoceima, Figure 16 shows that, values distribution, especially in the city center (center of the map), is random and doesn't follow any pattern, which is linked to the number of reinforcements and reconstructions in the area (Cherif et al. 2016). Values of $I_{y}$ index range between 0.3 and 1.93 with an average value of 0.82 , while $I_{u}$ index has values ranging between 0.32 and 2.13 with an average value of 1.2 .<smiles>NC1(F)NC1=[V]</smiles>

$$
\begin{array}{ll}
\text { ly index } \\
\qquad \quad<0.4 \\
\cdot \quad 0.4-0.7 \\
\quad 0.7-1 \\
\cdot \quad 1-1.3 \\
\cdot \quad 1.3-1.6 \\
\cdot \quad>1.6
\end{array}
$$
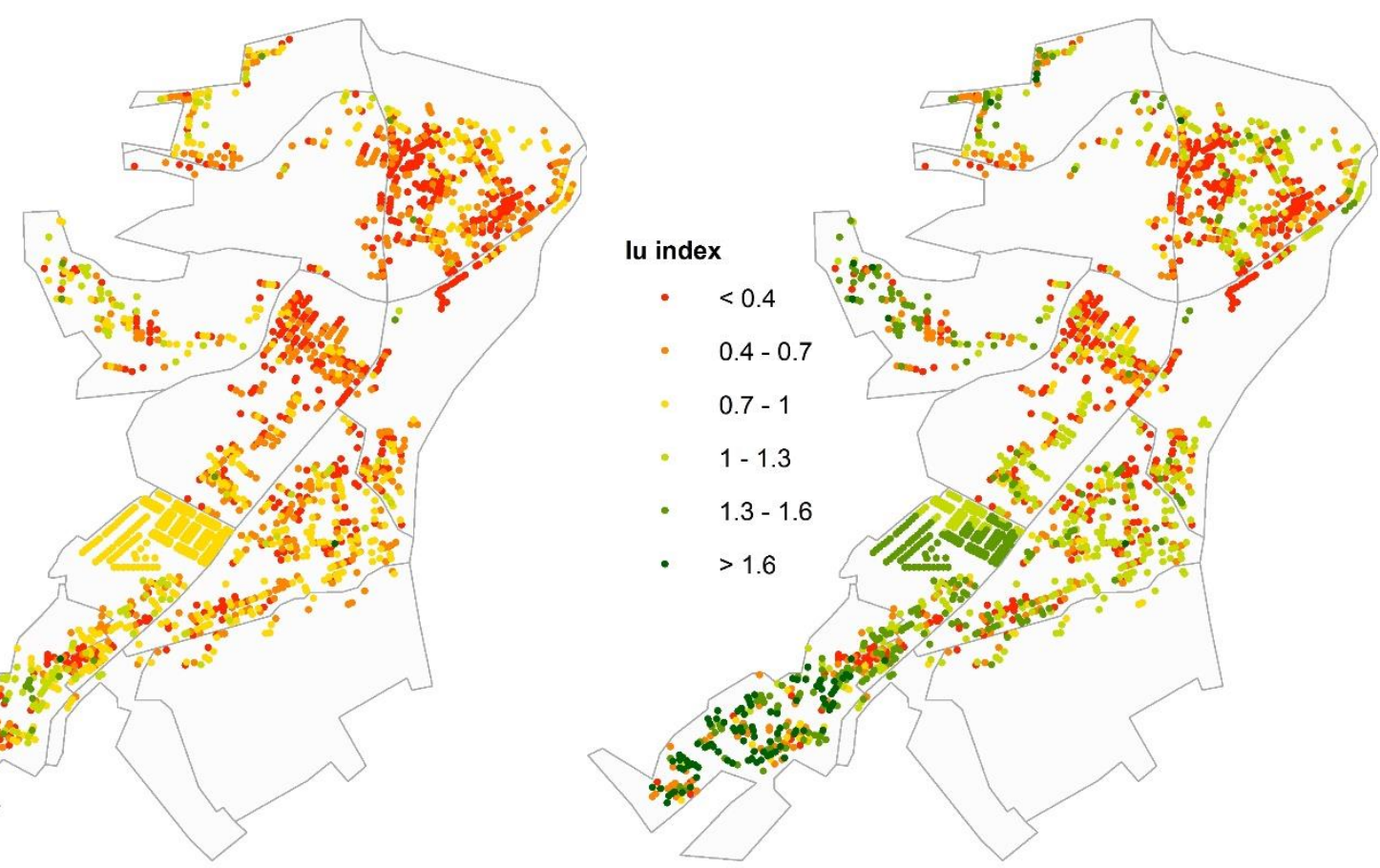


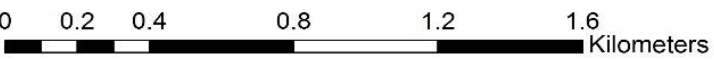

Fig. 15 Distribution of $I_{y}$ and $I_{u}$ indices in the city of Imzouren

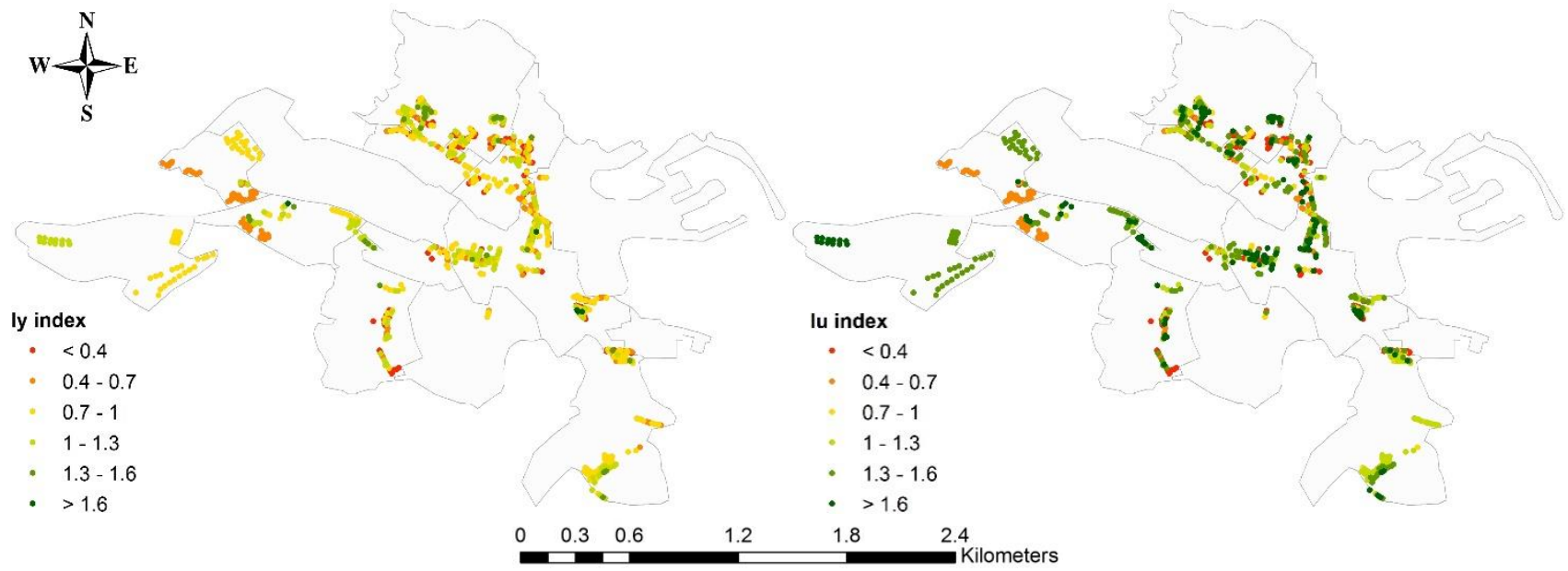

Fig. 16 Distribution of $I_{y}$ and $I_{u}$ indices in the city of Imzouren

The results were compared to past studies, including the seismic risk assessment of both cities using the RISK-UE method (Milutinoviç and Trendafiloski 2003) and EMS98 (Grünthal 1998). The probability of damage for existing buildings is inconclusive, since seismic demand differs from one study to another. However, the variation and distribution of values, for instance $I_{y}$ and $I_{u}$ for the present study and vulnerability index for the RISK-EU based study (Cherif et al. 2016) is very similar; The lowest values of the seismic indices correspond to high vulnerability indices in the north-western part of Al Hoceima and in the eastern part of Imzouren.

On February $24^{\text {th }}, 2004$ the northern region of Morocco was struck by a 6.4 magnitude earthquake (Jabour et al. 2004). The damage caused was catastrophic; 629 people died, 966 were injured and 15,600 homeless people (Tahayt et al. 2009). The estimated intensity in the city of Imzouren was in the range of IX-X degree of MSK scale (Talhaoui 2005) while it was estimated equal to VIII in the city of Al Hoceima (Cherkaoui and El Hassani 2012). A total number of 36 damaged buildings in the aftermath of the earthquake (Corella 2004; Goula and Gonzalez 2004; Jabour et al. 2004; Cherkaoui and Harnafi 2005) were studied and evaluated using the proposed method, in order to compare $I_{y}$ and $I_{u}$ values with the damage state observed for each construction.

Figure 17 shows the results of this comparison. As expected, the average values of each damage state are generally decreasing (Table 7), going from 0.58 for Slight damage to 0.44 for Collapse for $I_{y}$ values and from 0.81 for Slight damage to 0.45 for collapse for $I_{u}$ values, although $I_{u}$ decreasing pattern is more clearly expressed. $I_{y}$ values are all below 1, which explains the presence of damage in the first place. As for $I_{u}$ values, the results pattern was expected. As previously mentioned, the seismic demand is higher than what recent observed seismic activity has shown including the 2004 earthquake, since the objective is to further protect buildings. For instance, if we consider that the seismic demand is calibrated for this particular earthquake, instead of $I_{u}=I_{y}=1$ threshold limit, it would be between 0.6 and 0.65 , the results shown in Figure 17 would be very accurate (collapse and very heavy damages states average $I_{u}$ values are below 0.65 and all damage states average $I_{y}$ values are also below 0.65 ).

Table 7: Average $I_{y}$ and $I_{u}$ values of each damage state for the damaged buildings of the 2004 earthquake

\begin{tabular}{lccccc}
\hline Mean index & Slight & Moderate & Heavy & Very Heavy & Collapse \\
\hline $\mathrm{I}_{\mathrm{y}}$ & 0.575 & 0.503 & 0.533 & 0.439 & 0.443 \\
$\mathrm{I}_{\mathrm{u}}$ & 0.813 & 0.710 & 0.657 & 0.492 & 0.454 \\
\hline
\end{tabular}



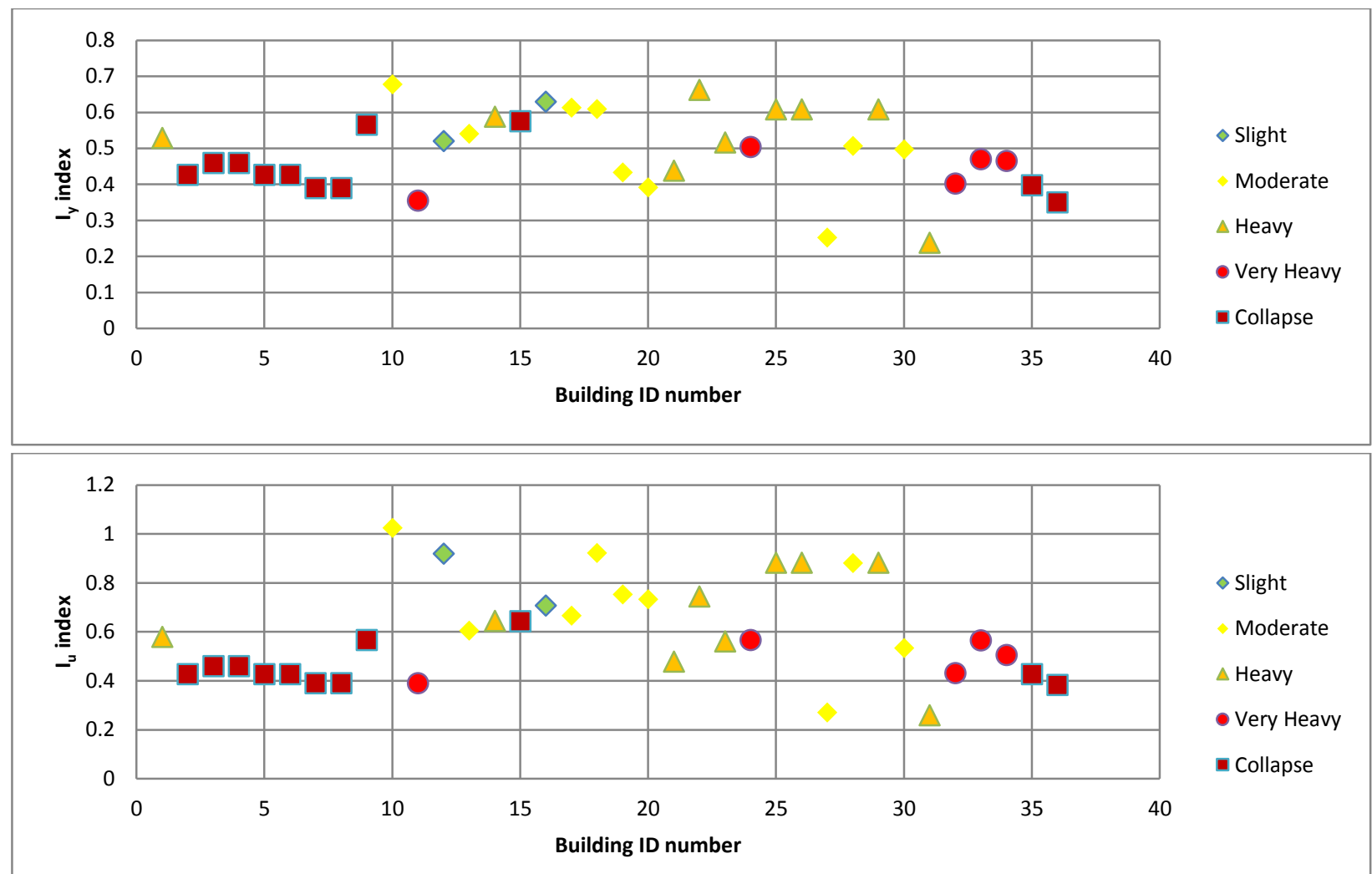

Fig. $17 I_{y}$ and $I_{u}$ values and Damage state for damaged buildings in the aftermath of the 2004 earthquake

\section{Conclusion}

Seismic evaluation of existing reinforced concrete buildings was carried out for the cities of Al Hoceima and Imzouren. The study was conducted using a screening method adapted to the context of Moroccan construction. The main objective was to make use of a procedure that is time-efficient, but at the same time, more in-depth than casual street surveys. This was accomplished by studying the structural elements of the common types of residential buildings in the two cities.

A building inspection was conducted prior to the study. A total of 2746 residential buildings were investigated for the purpose of this study; 35\% of Imzouren dwellings and $8 \%$ of Al Hoceima's were included. It was observed that most buildings were low to mid-rise RC moment frame structures, with simple geometrical forms and small floor areas. These results encouraged employing the proposed method, since most of the observed variations could be narrowed down to a limited number of models. 3D models were designed to represent the different typologies observed in $\mathrm{Al}$ Hoceima and Imzouren. 36 models were introduced based on number of stories, construction period and seismic standards. A nonlinear static pushover method approach was used in order to calculate capacity curves of the designed models.

The damage model is based on two global seismic indices, $I_{y}$ and $I_{u}$, representative of the main features of the building; $I_{y}$ is the yielding index, and $I_{u}$ is the ultimate capacity index. These global seismic indices are estimated using basic seismic indices, irregularity and time indices. One of the most important aspects of this study is the fact that buildings were not only defined by their capacity curves but also shape complexity and structural defects were included as well. This procedure made it possible to characterize each building with its own unique seismic index, $\left(I_{y}\right.$ or $\left.I_{u}\right)$. These seismic indices take values between 0.2 and 2.35 for $I_{y}$ and 0.22 and 2.6 for $I_{u}$. High seismic indices correspond to buildings showing a good seismic behaviour.

The results of this study show that almost all non-engineered buildings have low seismic indices (average values of $I_{y}=$ 0.42 and $I_{u}=0.46$ opposed to seismic buildings with average values of $I_{y}=0.92$ and $I_{u}=1.42$ ). Also non-engineered 
buildings are more exposed to damage in case of an earthquake. One of the most important aspects of seismic regulations is that buildings should have enough capacity to resist damage avoiding collapse. This statement is reflected in the aforementioned results, where $I_{y}$ and $I_{u}$ values are almost equal in case of non-engineered structures and fairly apart for constructions built with seismic regulations. The population of the studied area had experienced violent earthquakes before the 2000s. It would explain the fact that since then, seismic regulations are quite fairly followed. In fact, most of the constructions built after the 2000s, respect the seismic regulations; it is worth to mention that about $92 \%$ of new buildings are designed to withstand seismic loads.

Based on the results obtained, Imzouren is more exposed to damage than the city of Al Hoceima is. According to reports of observed seismic damage in the aftermath of the February $24^{\text {th }}, 2004$ earthquake that struck the northern region of Morocco, the damage was more significant in Imzouren than in Al Hoceima, even though the two cities were equidistant from the epicenter. It was reported that the damage differences were linked to the nature of soil and construction quality. While, it is almost impossible to check for the quality of construction for existing buildings, according to this study, the nature of soil definitely was a factor of the damage differences observed.

The proposed method shows results that concur with past studies and field reports from past earthquakes, which would help for city planning and risk mitigation in the area. The proposed procedure could even be considered for further studies in other cities and easily adapted if building typologies are carefully determined and capacity curves are well calculated.

\section{References}

Bezzeghoud M, Buforn E (1999) Source parameters of the 1992 Melilla (Spain, Mw = 4.8), 1994 Al Hoceima (Morocco $\mathrm{Mw}=5.8$ ) and Mascara (Algeria, Mw = 5.7) earthquakes and seismotectonic implications. Bull Seismol Soc Am 89:359-372

Cherif SE, Chourak M, Abed M, Pujades L (2017) Seismic risk in the city of Al Hoceima (north of Morocco) using the vulnerability index method, applied in Risk-UE project. Natural Hazards, 85(1), pp.329-347

Cherkaoui T, Hatzfeld D, Jebli H, Medina F, Caillot V (1990) Etude microsismique de la région d'Al Hoceima. Bull Inst Sci Rabat 4:25-34

Cherkaoui TE, Harnafi M (2005) Le séisme d'Al Hoceima du 24 février 2004. Trav. Col. Nat. Sur: Région de Taza-Al Hoceima-Taounate, ressources et stratégies de développement, Pub. Fac. Polydisciplinaire de Taza, (1), 27-38

Cherkaoui T, El Hassani A (2012) Seismicity and seismic hazard in Morocco 1901-2010. Bulletin de l'Institut Scientifique, Rabat, section Sciences de la Terre 2012(34):45-55

Computers and Structures Inc (1997) SAP2000, Integrated Finite Element Analysis and Design of Structures. Version 6.1 September 1997, Berkeley, California, USA

Corella (2004) Al Hoceima earthquake 2402 2004. Field report Patrick Murphy Corella Architect. June 2004

Douiri A, Mourabit T, Cheddadi A, Chourak M (2014) Pertinence de la méthode H/V « bruit de fond » pour l'évaluation de l'effet de site dans la ville d'Imzouren (Rif central, Maroc). Notes et Mém. Serv. Géol. du Maroc, Vol. 577, pp 16

El Alami SO, Tadili BA, Cherkaoui TE, Medina F, Ramdani M, Ait Brahim L, Harnafi M (1998) The Al Hoceima earthquake of May 26, 1994 and its aftershocks: a seismotectonic study. Ann. Geofisica 41:519-537

Federal Emergency Management Agency (FEMA) (1997) NEHRP guidelines for the seismic rehabilitation of buildings. Washington (DC): FEMA 273

FEMA 154 (1988) Rapid Visual Screening of Buildings for Potential Seismic Hazards - A Handbook, Federal Emergency Management Agency, Washington D.C.

FEMA 310 (1998) Handbook for the Seismic Evaluation of Buildings -A Prestandard, Federal Emergency Management Agency, Washington D.C., 1998

Goula X, Gonzalez M (2004) Visite technique à la zone endommagé par le séisme d'Al-hoceima du 24 février 2004. Generalitat de Catalunya. Institut Cartogra fic de Catalunya, ICC-GS-192/2004 (fr)

Grünthal G (1998) European macroseismic scale 1998. Centre Européen de Géodynamique et de Séismologie, Luxemburg

Guevara LT, Garcia LE (2005) The captive- and short-column effects. Earthquake Spectra, 21(1), p. 141-160 
Hassan AF, Sozen MA (1997) Seismic Vulnerability Assessment of Low-Rise Buildings in Regions with Infrequent Earthquakes, ACI Structural Journal, Vol. 94, No. 1, pp. 31-39

Jabour N, Kasmi M, Menzhi M, Birouk A, Hni L, Hahou Y, Timoulali Y, Bedrane S (2004) The February 24th, 2004 Al Hoceima earthquake, Newsletter of European-Mediterranean Seismological Centre, No 21, ISSN:1607-1980

JBDPA (2001) Standard for Seismic Evaluation of Existing Reinforced Concrete Buildings, Japan Building Disaster Prevention Association, 2001

Lagomarsino S, Giovinazzi S (2006) Macroseismic and mechanical models for the vulnerability and damage assessment of 453 current buildings. Bull Earthq Eng 4:415-443

Milutinoviç ZV, Trendafiloski GS (2003) WP04: vulnerability of current buildings handbook. RISK-UE project: an advanced approach to earthquake risk scenarios with applications to different European towns. Contract No. EVK4CT-2000-00014, Institute of Earthquake Engineering and Engineering Seismology (IZIIS), Skopje

Ozdemir P, Boduroglu MH, Ilki A (2005) Seismic Safety Screening Method. Proceedings of the International Workshop on Seismic Performance Assessment and Rehabilitation of Existing Buildings (SPEAR), Ispra, Italy, Paper No. 23 (on $\mathrm{CD}$ )

Prakash VG, Powell H, Campbell S (1993) DRAIN-2DX base program description and user guide. Report No: UCB. SEMM-93/17, University of California at Berkeley

PS92 (1995) Règles PS applicables aux bâtiments. NF P 06-013-DTU Règles PS 92, Décembre 1995

R.P.S. 2000 (2002) Règlement de construction parasismique. Ministère de l'Aménagement du Territoire, de l'Urbanisme, de l'Habitat et de l'Environnement. Secrétariat d'Etat à l'Habitat

R.P.S. 2000, Version 2011 (2011) Règlement de construction parasismique. Ministère de l'Habitat, de l'Urbanisme et de l'Aménagement de l'Espace

Tahayt A, Feigl KL, Mourabit TL, Rigo A, Reilinger R, McClusky S, Fadil A, Berthier E, Dorbath L, Serroukh M, Gomez F, Ben Sari D (2009) The Al Hoceima (Morocco) earthquake of 24 February 2004, analysis and interpretation of data from ENVISAT ASAR and SPOT5 validated by ground-based observations. Remote Sensing of Environment 113 (2009) 306-316. doi:10.1016/j.rse.2008.09.015

Talhaoui A (2005) Risques géologiques et activité sismique dans la région d'Al Hoceima : Impact sur l'environnement et l'aménagement- Thèse de doctorat, Fac. Sci., Univ. Rabat, 207p

Yakut A (2004) Preliminary Seismic Performance Assessment Procedure for Existing RC Buildings. Engineering Structures, Vol. 26, No. 10, pp. 1447-1461 